\section{IMPROVEMENT OF ECONOMIC CROP PLANTS}

$I^{\mathrm{N}}$ $\mathrm{N}$ these days when our thoughts tend to be concentrated on battle areas and the production of munitions of war, it is refreshing to turn to the no less essential researches and activities which have as their aim the increased production and improvement of economic plants, an activity which will also be of benefit to the world when peace is restored. For his presidential address to the thirty first Indian Science Congress held in January at Delhi, Dr. T. S. Sabnis chose as his topic the recent advances in botany in relation to improved crop production, and he is to be congratulated on the picture he has portrayed of the very varied avenues of botanical research which all converge and have their part in contributing to this ultimate aim.

Genetics is a relatively new science, and the astonishing advances since plant-breeding was placed upon a firm foundation by the re-discovery of Mendel's papers in 1900 justifies the placing of this subject in the forefront of such an address. In the period between the two Wars, a somewhat new impetus and outlook was introduced, particularly by the Russian plant-breeders under Dr. I. N. Vavilov, into the plant-breeding experiments, in that the latter were associated with widespread search and introduction of related cultivated and wild species from other parts of the world; this line met with considerable success, since new genes were introduced into the assemblage for assortment into combinations favourable for a wide variety of habitats; some of the wild species introduced genes of increased hardiness and disease resistance which would prove of very great value if combined with some of the properties of eultivated forms. The difficulties of inducing crosses between desired types were much reduced by the discovery that sterility of interspecific, or even intergeneric, hybrids might be overcome by artificial induction of polyploidy by the use of colchicine or X-ray treatments. Thus polyploid crosses between wheats and Agropyrum elongatum gave promise of perennial wheats with high yield and disease resistance combined with such hardiness that they would grow in regions previously considered impossible for cultivation of wheat. Polyploidy has also been shown to have its uses in contributing greater vigour to certain types and increasing the yields of certain plant constituents, such as the vitamin $\mathrm{C}$ content of tomatoes and the carotinoid content of maize.

Once the significance of introducing new types into the assemblage for interbreeding isrealized,it is obvious that the plant geographer who studies the distribution of species, the pure systematist who names the plants, the ecologist who studies their relationships to the normal habitat, and the botanist who is interested in the subdivision of the species into varieties and microspecies, will all have their contribution to make to the successful cultivation of the plants concermed, and the possibilities of their hybridization and introduction as crop plants into new and previously uncultivated regions. The relation of the plant to its environment is in itself a large problem, and considerable light has been thrown on this type of study by the somewhat new aspects of the work elaborated by Clements. He has taken a more dynamic view of the vegetation, and his conception of climax, succession and conservation has stressed the importance of following the changes in a vegetation and has given results of importance particularly in relation to grassland and forest cultivation.

In the field of plant physiology, the work of Gardiner and Allard on photoperiodism has enabled a technique to be evolved for bringing plants collected from different climatic zones into the flowering condition at the same time and thus rendering their hybridization a possibility.

Another important aspect of plant cultivation in new regions was the discovery by Lysenko of 'vernalization'. Previously, many plants were confined within certain temperature zones, beyond which they could not be cultivated, but Lysenko showed that by careful regulation of temperature treatment of seed the climatic barrier could be broken down; for example, many varieties of winter wheats which would not ear when sown in spring could be made to do so by vernalization.

These are the main factors discussed by Dr. Sabnis in connexion with the production of new varieties of economic plants with improved qualities, or with wider ranges of cultivation in relation to climatic or soil conditions. He referred also to the significance of certain other aspects of botanical research, such as the utilization of certain chemicals to promote root-growth, which has played an important part in problems of vegetative propagation, and the recognition of the importance of secondary elements. It is not long since only those elements necessary to plants in relatively large amounts were recognized as essential, but it is now known that other elements such as boron, zinc, silicon, etc., may be responsible for deficiency diseases and failures of certain crops, though the quantities required are extremely small.

\section{CHROMOSOMIN' AND NUCLEIC ACIDS}

TN a recent article, Stedman and Stedman ${ }^{1}$ have reported observations which they consider to indicate the existence of a special protein, termed 'chromosomin', in cell nuclei ; and, on theoretical grounds, have endeavoured to ascribe to it several previously known phenomena considered to be due to other nuclear constituents, especially nucleic acids. As regards nucleic acids, Callan ${ }^{2}$ has put forward the experimental data against their view; Stedman and Stedman ${ }^{3}$ have based their reply to Callan largely on references to data from my laboratory. As no reference is given to the original papers, and I regard the comments as directly misleading, a brief correction appears to be called for ; in particular, it seems desirable to indicate my view of the bearing of the ultra-violet absorption measurements on the 'chromosomin' question. 'This is all the more necessary as Stedman and Stedman, by the wording of their communication ${ }^{3}$, convey the impression of a thorough study (p. 504, "if one examines Caspersson's work critically one will find, as he himself admits, that ..."), whereas of some twenty-five publications bearing on this subject, issued from 1936 onwards, only the very first has been available in the original.

Stedman intimates (p. 504) that the absorption band in the nuclear material which I had attributed to nucleic acids may actually have been caused by tryptophane. In 1936 the first two absorption spectra obtained by a photographic process were recorded by me*. By evidence to which Stedman does not refer, it was shown that these spectra were due to a 